\title{
超高強度ラインパイプX100〜 X120*
}

\author{
石 川 信 行 $^{* *}$
}

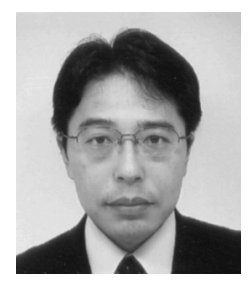

Ultra high strength Linepipe X100-X120*

by ISHIKAWA Nobuyuki ${ }^{* *}$

キーワード 天然ガス, ラインパイプ, 規格化, 高強度, 高変形能, 溶接性

\section{1.はじめに}

世界的なエネルギー需要の増大と $\mathrm{CO}_{2}$ 排出の少ないク リーンエネルギーへの要求から, 近年天然ガスの需要が拡 大している. 天然ガス輸送用パイプラインのトータルコス 卜削減のため, 操業圧力の高圧化とともに使用鋼材量の低 減と現地溶接施工コスト削減が可能な高強度ラインパイ プに対する要求がさらに高まっている1-2)。このため, 近年 API X70 およびX80 グレード (API：アメリカ石油協会) の高強度ラインパイプの適用が増えており 3.4 ,, 2002 年に はX100 が初めて実用化された ${ }^{5}$.また，X120 グレードの ラインパイプの開発も盛んに進められている ${ }^{6-9}$. 一方, パ イプラインの建設は環境の厳しい地域へ拡大しており,特 に地震地帯や不連続凍土地帯などへ敷設されるラインパ イプに対しては, 地盤変動によるパイプの変形に対して局 部座屈や円周溶接部からの破壊が生じないような十分な 変形性能が必要とされている. しかし，一般的に高強度化 に従い一様伸びや降伏比などで示される変形能が低下す るため，X100 グレード以上の高強度ラインパイプを実用
化するための大きな課題となっている.

本稿では，近年実用化が進んでいるX100 グレードライ ンパイプの適用状況とその母材及び溶接部性能, そして, さらに高強度の X120 グレードラインパイプの開発状況に ついて紹介する。

\section{2. 超高強度ラインパイプの規格化}

ラインパイプの規格には, 従来からの API 5L や ISO 3183，また海底パイプラインの規格である DNV OS-F101 等が適用されている.従来は X80 グレードまでが規格化さ れていたが, 近年の高強度ラインパイプのニーズに応じ て, X100 グレード以上の規格化が進んでいる. 初めて $\mathrm{X} 100$ が規格化されたのは, カナダのパイプライン規格 CSA Z245.1 (Grade 690) であり, 現在 X100 グレード以上 の高強度ラインパイプが実ラインへ敷設されているのは カナダのみである.一方, 国際規格である ISO においても 従来の X80 グレードを超える高強度ラインパイプの規格 化作業が進められ，2007 年には ISO $3183 に X 90 〜 X 120$ のラインパイプ規格が追加された。表 1 及び表 2 に ISO

表 1 高強度ラインパイプの化学成分（ISO 3183 )

\begin{tabular}{|c|c|c|c|c|c|c|c|c|c|c|c|c|c|}
\hline \multirow[t]{2}{*}{ Pipe grade } & \multicolumn{11}{|c|}{$\begin{array}{l}\text { Mass fraction, based upon heat and product analyses } \\
\% \text { maximum }\end{array}$} & \multicolumn{2}{|c|}{$\begin{array}{l}\text { Carbon equivalent } \\
\% \text { maximum }\end{array}$} \\
\hline & C & $\mathrm{Si}$ & Mn & $P$ & s & $\mathrm{Cu}$ & $\mathrm{Ni}$ & $\mathrm{Cr}$ & Mo & $|\mathrm{V}+\mathrm{Nb}+\mathrm{Ti}|$ & B & $C E_{\| W}{ }^{1)}$ & $\left(\mathrm{CE}_{\mathrm{Pcm}}{ }^{2)}\right.$ \\
\hline L555 or X80M & \begin{tabular}{|l|}
0.12 \\
\end{tabular} & 0.45 & 1.85 & 0.025 & 0.015 & 0.5 & 0.5 & 0.5 & 0.5 & 0.15 & & 0.43 & 0.25 \\
\hline L690 or X100M & 0.10 & 0.55 & 2.10 & 0.020 & \begin{tabular}{|l|}
0.010 \\
\end{tabular} & 0.5 & 0.5 & 0.5 & 0.5 & 0.15 & 0.004 & - & 0.25 \\
\hline L830 or X120M & 0.10 & 0.55 & 2.10 & 0.020 & \begin{tabular}{|l|}
0.010 \\
\end{tabular} & 0.5 & 1.0 & 0.5 & 0.5 & 0.15 & 0.004 & - & 0.25 \\
\hline
\end{tabular}

*原稿受付 平成21 年7月6日

**正員 JFE スチール(株) スチール研究所 Member, Steel Research Laboratories, JFE Steel Corporation 
表 2 高強度ラインパイプの引張性能（ISO $3183 ）$

\begin{tabular}{|c|c|c|c|c|c|c|c|}
\hline \multirow{3}{*}{ Pipe grade } & \multicolumn{6}{|c|}{ Pipe body } & \multirow{3}{*}{$\begin{array}{c}\text { Weld seam } \\
\text { Tensile strength } \\
R_{\mathrm{m}}(\mathrm{MPa}) \\
\text { min }\end{array}$} \\
\hline & \multicolumn{2}{|c|}{$\begin{array}{c}\text { Yield strength } \\
R_{\mathrm{t} 0.5}(\mathrm{MPa})\end{array}$} & \multicolumn{2}{|c|}{$\begin{array}{c}\text { Tensile strength } \\
R_{\mathrm{m}}(\mathrm{MPa})\end{array}$} & \multirow{2}{*}{$\begin{array}{c}\text { Ratio } \\
R_{\mathrm{t} 0.5} / R_{\mathrm{m}} \\
\max \end{array}$} & \multirow{2}{*}{$\begin{array}{c}\text { Elongation } \\
A_{\mathrm{f}}(\%) \\
\min \\
\end{array}$} & \\
\hline & $\min$ & $\max$ & $\min$ & $\max$ & & & \\
\hline L555 or X80M & 555 & 705 & 625 & 825 & 0.93 & 3) & 625 \\
\hline L690 or X100M & 690 & 840 & 760 & 990 & 0.97 & 3) & 760 \\
\hline L830 or X120M & 830 & 1050 & 915 & 1145 & 0.99 & 3) & 915 \\
\hline
\end{tabular}

$A_{\mathrm{xc}}$ : applicable tensile test piece cross-section area, $U$ : specified minimum tensile strength

表 3 高変形 X100 ラインパイプの要求性能

\begin{tabular}{|c|c|c|c|c|c|c|c|c|c|c|c|c|c|c|c|}
\hline \multirow{3}{*}{ Grade } & \multicolumn{4}{|c|}{ Pipe Body - Transverse ${ }^{* 1}$} & \multicolumn{9}{|c|}{ Pipe Body - Longitudinal ${ }^{* 2}$} & \multicolumn{2}{|c|}{ Weld Tensile } \\
\hline & \multirow{2}{*}{$\begin{array}{l}\mathrm{YS}^{* 3} \\
(\mathrm{MPa})\end{array}$} & \multirow{2}{*}{$\begin{array}{c}\mathrm{TS} \\
(\mathrm{MPa})\end{array}$} & \multirow{2}{*}{$\begin{array}{l}\text { EL } \\
(\%)\end{array}$} & \multirow{2}{*}{$\begin{array}{l}\mathrm{Y} / \mathrm{T} \\
(\%)\end{array}$} & \multirow{2}{*}{$\begin{array}{c}\mathrm{YS}^{* 3} \\
(\mathrm{MPa})\end{array}$} & \multirow{2}{*}{$\begin{array}{c}\mathrm{TS} \\
(\mathrm{MPa})\end{array}$} & \multirow{2}{*}{$\begin{array}{c}\text { EL } \\
(\%)\end{array}$} & \multirow{2}{*}{$\begin{array}{c}\mathrm{uEl}^{* 4} \\
(\%)\end{array}$} & \multirow{2}{*}{$\begin{array}{l}\mathrm{Y} / \mathrm{T} \\
(\%)\end{array}$} & \multicolumn{4}{|c|}{ Stress ratio ${ }^{* 5}$} & \multirow{2}{*}{$\begin{array}{c}\text { TS } \\
(\mathrm{MPa})\end{array}$} & \multirow{2}{*}{$\begin{array}{l}\text { EL } \\
(\%)\end{array}$} \\
\hline & & & & & & & & & & $\sigma_{\mathrm{b}} / \sigma_{\mathrm{a}}$ & $\sigma_{\mathrm{c}} / \sigma_{\mathrm{b}}$ & $\sigma_{d} / \sigma_{c}$ & $\sigma_{\mathrm{e}} / \sigma_{\mathrm{d}}$ & & \\
\hline & $690-$ & $760-$ & Min. & Max. & $620-$ & $760-$ & Min. & Min. & Max. & Min. & Min. & Min. & Min. & Min & M \\
\hline G690 & 825 & 970 & 10 & 95 & 750 & 970 & 17 & 4.0 & 93 & 1.04 & 1.03 & 1.03 & 1.02 & 760 & 10 \\
\hline
\end{tabular}

*1 Trans.: Round bar specimen *2 Longi.: Rectangular strip specimen * 3 YS: Rt0.5 *4 uEl: Uniform elongation

${ }^{*} 5 \sigma_{\mathrm{a}}$ : Stress at $\varepsilon=0.4 \%, \sigma_{\mathrm{b}}$ : Stress at $\varepsilon=0.5 \%, \sigma_{\mathrm{c}}$ : Stress at $\varepsilon=0.6 \%, \sigma_{\mathrm{d}}$ : Stress at $\varepsilon=0.8 \%, \sigma_{\mathrm{e}}$ : Stress at $\varepsilon=1.0 \%$

表 4 高変形 X100 ラインパイプの化学成分

\begin{tabular}{c|c|c|c|c|c|c}
\hline $\mathrm{C}$ & $\mathrm{Si}$ & $\mathrm{Mn}$ & $\mathrm{Mo}$ & others & $\mathrm{CE}(\mathrm{CSA})$ & Pcm \\
\hline 0.07 & 0.10 & 1.85 & 0.20 & $\mathrm{Cu}, \mathrm{Ni}, \mathrm{Nb}, \mathrm{Ti}$ & 0.29 & 0.20 \\
\hline
\end{tabular}

$\mathrm{CE}=\mathrm{C}+\mathrm{F}\{\mathrm{Mn} / 6+\mathrm{Si} / 24+\mathrm{Cu} / 15+\mathrm{Ni} / 20+(\mathrm{Cr}+\mathrm{Mo}+\mathrm{Nb}+\mathrm{V}) / 5+5 \mathrm{~B}\}, \mathrm{F}=0.56$

$\mathrm{Pcm}=\mathrm{C}+\mathrm{Si} / 30+(\mathrm{Mn}+\mathrm{Cu}+\mathrm{Cr}) / 20+\mathrm{Mo} / 15+\mathrm{Ni} / 60+\mathrm{V} / 10+5 \mathrm{~B}$

3183 に示されているX80 以上の化学成分及び引張特性の 要求值を示す.化学成分は，X100-X120 では高強度を得る ために Mn や Ni の上限が引き上げられ， B 添加も可能と なっている。一方，溶接性を確保するために C 添加量が $0.10 \%$ 以下に抑えられ, $\mathrm{Pcm}\left(\mathrm{CE}_{\mathrm{Pcm}}\right)$ も X80 と同レベルに 維持されている。規格下限引張強度 $(\mathrm{Rm}, \mathrm{min})$ は, X100 で760MPa，X120 で $915 \mathrm{MPa}$ に高められたが，降伏比 (Rt0.5/Rm) は X100 で $0.97, \mathrm{X} 120$ で 0.99 に緩和されてい る.このように, X100 以上の高強度ラインパイプの材料規 格が整備されてきており, 今後その適用がさらに進むもの と考えられる。

\section{3. 高変形 X100 ラインパイプの実用化}

ラインパイプの強度グレードは 1980 年代に API X80 (降伏強度 $550 \mathrm{MPa}$ 以上) が規格化, 実用化され, それ以降 高強度化の研究開発が盛んに進められてきた. X100（降伏 強度 $690 \mathrm{MPa}$ 以上) も早くから開発が進み ${ }^{10,11)}, 2002$ 年に は実ラインへ適用された後 ${ }^{6}, 2004$ 年にはカナダ北部の厳 寒地において冬季敷設が行われ, 高い溶接施工性と母材及 び溶接部性能が証明されている ${ }^{12)}$. また, X100 ラインパイ プ適用に向けた実証試験も盛んに進められている ${ }^{13,14) . さ ~}$ らに, 将来の凍土地带での長距離パイプラインへの適用を 目指して, 2000 トンにも及ぶ高変形 X100 ラインパイプの 量産化とカナダ東部でのパイプライン敷設も行われてい る ${ }^{15)}$. 以下にその概略を紹介する.

凍土地帯では地盤変動による埋設パイプラインの損傷 を防止するために, 使用されるラインパイプには高い変形

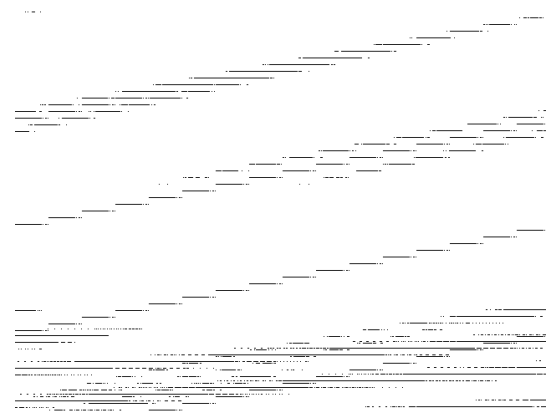

図 1 応力比の定義

性能が要求される. 表 3 にその要求性能を示す. 鋼管の管 周方向強度に加え, 管軸方向の引張特性も必要であり, $4 \%$ 以上の一様伸びと $93 \%$ 以下の降伏比, さらには連続降伏 型の応力歪み曲線を保証するために, 様々な歪みレベルで の応力比が規定されている. 図 1 に応力比の定義を示す. 応力比はある歪み範囲での応力值の比であり, この場合 は，0.4\%から 1.0\%の範囲を細かく区切り，それぞれの範 囲で応力值が一定值以上とすることで, 降伏棚のない連続 降伏型の応力歪み曲線が保証されることになる.

このような要求性能を満足するために, ラインパイプ用 の鋼板製造においては，最新の TMCP 技術（ThermoMechanical Controlled Processing）を駆使した複相組織 制御技術が適用された. 制御圧延と加速冷却条件の制御に よりミクロ組織をフェライトーベイナイト二相組織とす ることで高い変形性能が得られる ${ }^{16-18)}$. さらに, 不安定延 性破壊防止に必要な母材シャルピーエネルギーを安定的 
表 5 高変形 X100 ラインパイプの引張特性

\begin{tabular}{|c|c|c|c|c|c|}
\hline \multicolumn{3}{|c|}{ Pipe Body - Transverse } & \multicolumn{2}{c|}{ Weld Tensile } \\
\hline $\begin{array}{c}\text { YS } \\
(\mathrm{MPa})\end{array}$ & $\begin{array}{c}\text { TS } \\
(\mathrm{MPa})\end{array}$ & $\begin{array}{c}\text { EL } \\
(\%)\end{array}$ & $\begin{array}{c}\text { Y/T } \\
(\%)\end{array}$ & $\begin{array}{c}\text { TS } \\
(\mathrm{MPa})\end{array}$ & $\begin{array}{c}\text { EL } \\
(\%)\end{array}$ \\
\hline 783 & 844 & 23 & 93 & 796 & 21 \\
\hline
\end{tabular}

\begin{tabular}{|c|c|c|c|c|c|c|c|}
\hline \multicolumn{10}{|c|}{ Pipe Body - Longitudinal } \\
\hline YS & TS & uEl & Y/T & \multicolumn{5}{|c|}{ Stress ratio } \\
\cline { 5 - 8 }$(\mathrm{MPa})$ & $(\mathrm{MPa})$ & $(\%)$ & $(\%)$ & $0_{\mathrm{b}} / 0_{\mathrm{a}}$ & $0_{\mathrm{d}} / 0_{\mathrm{b}}$ & $0_{\mathrm{d}} / 0_{\mathrm{c}}$ & $0_{\mathrm{e}} / 0_{\mathrm{d}}$ \\
\hline 656 & 813 & 4.9 & 81 & 1.09 & 1.06 & 1.07 & 1.04 \\
\hline
\end{tabular}

表 $6 \times 100$ ラインパイプの円周溶接条件

\begin{tabular}{|c|c|c|c|}
\hline \multicolumn{2}{|c|}{ Welding process } & \multicolumn{2}{|l|}{ GMAW } \\
\hline \multicolumn{2}{|c|}{ Shielding gas } & \multicolumn{2}{|l|}{$\mathrm{Ar}+\mathrm{CO} 2$} \\
\hline \multicolumn{2}{|c|}{ Preheat temp } & \multicolumn{2}{|l|}{$100-135^{\circ} \mathrm{C}$} \\
\hline Pass & $\begin{array}{c}\text { Amperage } \\
\text { (A) }\end{array}$ & $\begin{array}{c}\text { Voltage } \\
\text { (V) }\end{array}$ & $\begin{array}{c}\text { Heat input } \\
(\mathrm{kJ} / \mathrm{mm})\end{array}$ \\
\hline Root & 200 & 20 & 0.33 \\
\hline Hot & 225 & 24 & 0.26 \\
\hline Fill & 180 & 19 & 0.45 \\
\hline Cap & 125 & 23 & 0.34 \\
\hline
\end{tabular}

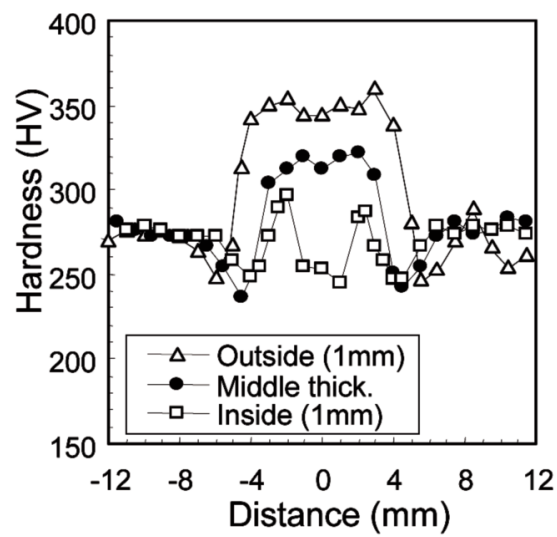

図 2 円周溶接部のマク口組織及び硬さ分布
に確保するために，オンライン熱処理技術（HOP: Heat treatment On-line Process）も適用されている.

表 4 に高変形X100 ラインパイプの化学成分を示す. 溶 接性を確保するため, $\mathrm{Pcm}$ は低く抑えられている。 そし て, UOE プロセスにより外径 $1067 \mathrm{~mm}$, 管厚 $14.3 \mathrm{~mm}$ の鋼 管を製造した。表 5 に高変形X100 ラインパイプの引張特 性を示す．製造した全ヒートの平均值であるが，管軸方向 引張特性において，高い一様伸びと，低降伏比，さらに規 定された歪み範囲において高い応力比が達成されている. また，母材シャルピーエネルギーも全ヒート平均で 294J の高い值が安定して得られている. その他，シーム溶接部 靱性やDWTT 性能等の必要性能も安定して得られてお り，2000トンを超えるX100 ラインパイプの大量製造が問 題なく達成された。

\section{X100 ラインパイプの円周溶接部性能}

ラインパイプは敷設現場へ輸送された後に, 現地で円周 溶接が行われるが, 長距離パイプライン建設においては溶 接施工性と円周溶接部の安定した品質を得ることが重要 となる. 高強度ラインパイプに適用するための, 高能率, 高 性能の溶接技術も多く開発されている ${ }^{19,20)}$. 以下に GMAW によるX100 ラインパイプ円周溶接部の性能を紹 介する。

前節の高変形 X100 ラインパイプを用いて，現地溶接と 同じ条件の円周溶接を実施した。施工能率を高めるため, 溶接トーチを 2 台連ねたタンデム型の GMAW であり，電 流波形にはパルス電流を適用した. 表 6 に円周溶接条件を 示す. 溶接材料は十分な強度と勒性を達成するために最適

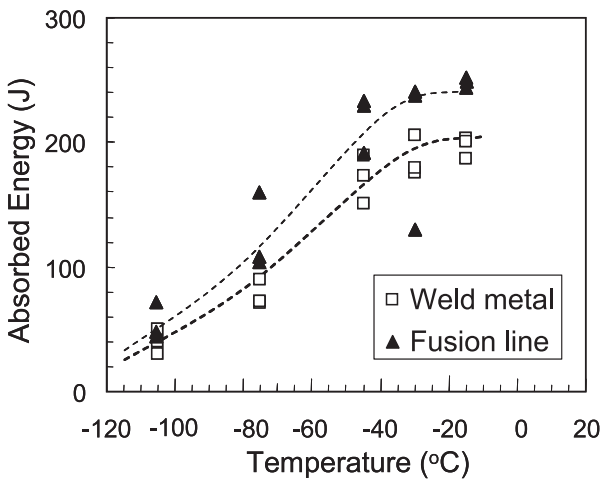

図 3 円周溶接部のシャルピ一試験結果

表 7 円周溶接部の CTOD 試験結果

\begin{tabular}{|c|c|c|c|c|}
\hline \multirow{2}{*}{ Notch position } & \multicolumn{4}{|c|}{ CTOD (mm) at $-15^{\circ} \mathrm{C}$ (BxB specimen) } \\
\cline { 2 - 5 } & 1 & 2 & 3 & Ave. \\
\hline Weld metal & 0.155 & 0.145 & 0.171 & 0.157 \\
\hline Fusion line & 0.274 & $(0.192)^{*}$ & 0.291 & 0.283 \\
\hline \multicolumn{5}{|c}{$*$ invalid $\left(\mathrm{a}_{0} / \mathrm{W}>0.55\right)$} \\
\hline
\end{tabular}

化されており, 溶接後の超音波探傷において久陷は検出さ れていない. 図 2 に (1) 溶接部のマクロ組織及び (2) 硬さ 分布を示す. 熱影響部の幅は $1 \mathrm{~mm}$ 程度と狭く, 顕著な HAZ 軟化は見られない. 円周溶接部の継手引張試験にお いても母材強度以上の高い引張強度が示されており, 図 2 (b) の硬さ分布からも明らかなように，オーバーマッチ継 手が問題なく達成されている.

図 3 に円周溶接部のシャルピー試験でのエネルギー遷 
移曲線を示す.溶接金属及び Fusion line (溶接金属と熱影 響部が $1: 1$ となる位置) ともに, $-40^{\circ} \mathrm{C}$ まで安定した高い 吸収エネルギーが得られている. また, 表 7 に示すように, CTOD 試験においても高い破壊鞀性を示している。この ような優れた円周溶接部性能は実ラインの現地溶接にお いても達成されており，X100 ラインパイプの母材成分の 適正化と最新の円周溶接技術の適用によって, 高能率でか つ高性能な円周溶接技術が既に実用化されている。

\section{X120 ラインパイプの開発状況}

$\mathrm{X} 100, \mathrm{X} 120$ ラインパイプ用鋼板は,優れた溶接性と母材 勒性を得るために $0.1 \%$ 以下の低 $\mathrm{C}$ 鋼 ${ }^{21}$ を用いて TMCP 技術，特に加速冷却技術を最大限活用して作られている. X100 までのミクロ組織は上部ベイナイトが主体となる が，X120ではさらに高強度化するために下部べイナイト 組織が活用されている ${ }^{22-24)}$. 合金成分としてボロン (B) を 添加することが有効であり，さらに低い加速冷却停止温度 を適用することで，下部べイナイト組織が得られる.また， ボロン添加は母材の強度を高めるだけでなく, シーム溶接 部の溶接熱影響部 (HAZ) の組織も下部ベイナイト化され HAZ 勒性向上にも有効とされている ${ }^{23}$. X120 ラインパイ プは現状の内圧設計のパイプラインへは十分適用可能と 考えられており，X100 と同様に実ラインへの敷設試験も 行われている ${ }^{25)}$.

その一方で, 高強度になるほど伸び変形能が低くなるこ とが指摘されており ${ }^{26)}$, 加速冷却時に冷却速度を変化させ ることで，一様伸び性能を改善したX120 ラインパイプや ${ }^{27}$, 伸び性能の低いベイナイト単一組織ではなく, フェライ トーベイナイト二相組織とした高一様伸びの X120 ライン パイプなども開発されている ${ }^{9}$.ここでは,フェライトーべ イナイト型の高変形X120 ラインパイプの特徵を紹介す る.

ボロン（B）は焼入れ性の高い元素であり，加速冷却に より高強度を得るにはきわめて有効な元素である。しか し，ボロン添加鋼ではフェライトーベイナイト二相組織を 得ることが困難となる．図 4 は B 非添加鋼および B 添加 鋼の加工 CCT 図 (連続冷却変態線図) を示す. B 非添加鋼 では空冷に相当する低冷却速度では約 $700^{\circ} \mathrm{C}$ 付近でフェ ライトが生成することがわかるが, $\mathrm{B}$ 添加鋼では遅い冷却 速度でもフェライトが生成せずいずれの冷却速度でもべ イナイト単一組織となる。よって，フェライトーベイナイ 卜二相組織を得るためには B 非添加鋼を適用することが 必要である. 図 5 に実験室で製造した鋼板の一様伸びと引 張強度の関係を示す. B 非添加はフェライトーベイナイト 二相組織鋼であり，B 添加鋼に比べ高い一様伸びを示して いることが明らかである。

このような検討結果を基に, $\mathrm{B}$ 非添加鋼によるフェライ トーベイナイト型 X120 ラインパイプの実機による製造を 行った. 表 8 に化学成分を示す. B は非添加であり，溶接 性を考慮して Pcm は低く抑えられている。TMCPにより 板厚 $19 \mathrm{~mm}$ の鋼板を製造したが，シャルピーエネルギー を安定させる目的で，オンライン熱処理も適用している。 そして, UOE プロセスにより外径 $914.4 \mathrm{~mm}$ の鋼管に製造

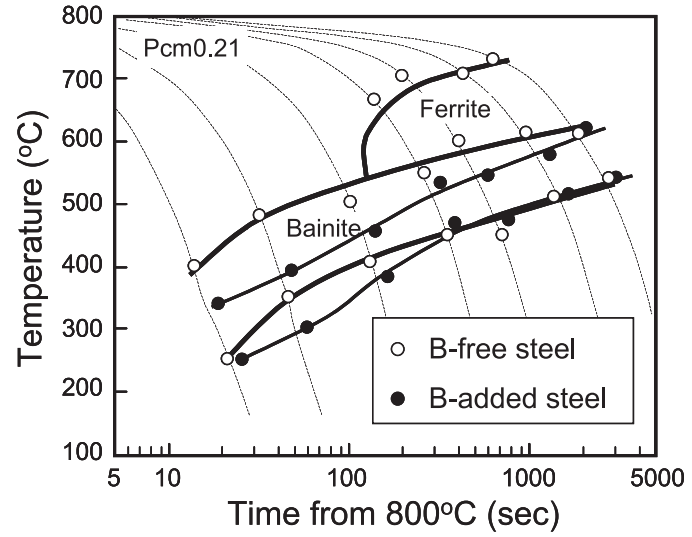

図 $4 \quad B$ 添加鋼及び B 非添加鋼の CCT 曲線

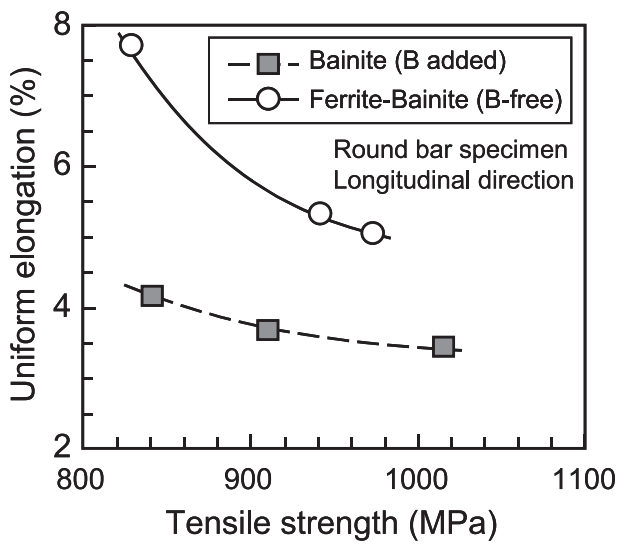

図 5 B 添加鋼及び B 非添加鋼の一様伸びと引張強度の関係

表 $8 \times 120$ ラインパイプの化学成分

\begin{tabular}{|c|c|c|c|c|c|}
\hline \multicolumn{1}{|c|}{} & (mass. \%) \\
\hline 0.06 & 0.15 & 1.91 & 0.27 & others & 0.22 \\
\hline
\end{tabular}

$\mathrm{Pcm}=\mathrm{C}+\mathrm{Si} / 30+\mathrm{Mn} / 20+\mathrm{Cu} / 20+\mathrm{Ni} / 60+\mathrm{Cr} / 20+\mathrm{Mo} / 15+\mathrm{V} / 10+5 \mathrm{~B}$

表 $9 \times 120$ ラインパイプの機械的特性

\begin{tabular}{|c|c|c|c|c|c|c|c|c|c|c|}
\hline \multirow{2}{*}{$\begin{array}{c}\text { Pipe } \\
\text { No. }\end{array}$} & \multicolumn{9}{|c|}{ Transverse } & \multicolumn{6}{|c|}{$\begin{array}{c}\text { Trans- } \\
\text { weld }\end{array}$} \\
\cline { 2 - 11 } & $\begin{array}{c}\text { YS } \\
(\mathrm{MPa})\end{array}$ & $\begin{array}{c}\text { TS } \\
(\mathrm{MPa})\end{array}$ & $\begin{array}{c}\mathrm{Y} / \mathrm{T} \\
(\%)\end{array}$ & $\begin{array}{c}\mathrm{EL} \\
(\%)\end{array}$ & $\begin{array}{c}\text { YS } \\
(\mathrm{MPa})\end{array}$ & $\begin{array}{c}\mathrm{TS} \\
(\mathrm{MPa})\end{array}$ & $\begin{array}{c}\mathrm{Y} / \mathrm{T} \\
(\%)\end{array}$ & $\begin{array}{c}\mathrm{EL} \\
(\%)\end{array}$ & $\begin{array}{c}\text { uEL } \\
(\%)\end{array}$ & $\begin{array}{c}\text { TS } \\
(\mathrm{MPa})\end{array}$ \\
\hline 1 & 906 & 934 & 97 & 18 & 750 & 920 & 82 & 29 & 4.0 & 932 \\
\hline 2 & 840 & 958 & 88 & 19 & 743 & 963 & 77 & 30 & 4.8 & 952 \\
\hline
\end{tabular}

\begin{tabular}{|c|c|c|c|cc|c|}
\hline \multirow{2}{*}{$\begin{array}{c}\text { Pipe } \\
\text { No. }\end{array}$} & \multicolumn{3}{|c|}{ Charpy Test } & \multicolumn{3}{c|}{ DWTT properties } \\
\cline { 2 - 6 } & $\begin{array}{c}\text { vE at -30o } \\
\text { Base } \\
\text { metal }\end{array}$ & HAZ & $\begin{array}{c}\text { Weld } \\
\text { metal }\end{array}$ & $\begin{array}{c}\text { Sat-20oC } \\
(\mathrm{J})\end{array}$ & $\begin{array}{c}85 \% \text { SATT } \\
\text { (oC) }\end{array}$ \\
\hline 1 & 263 & 119 & 65 & 86 & 91 & -25 \\
\hline 2 & 211 & 77 & 60 & 89 & 83 & -22 \\
\hline
\end{tabular}

した。表 9 にX120 ラインパイプの機械的特性を示す. X120 グレードとして十分な管周方向強度が得られてお り，管軸方向の特性として，85\%以下の低降伏比と $4 \%$ 以 上の高い一様伸びが達成されている．また，シャルピー衝 撃特性及び DWTT 性能も十分な性能が示されている. 図 


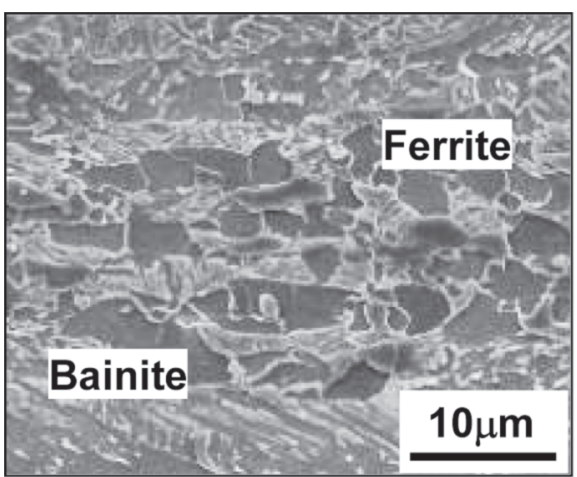

図 6 X120 ラインパイプのミクロ組織

5 にX120 ラインパイプのミクロ組織を示す.フェライ トーベイナイト二相組織でかつ十分な分率の微細ポリゴ ナルフェライトが見られる。これによって高い一様伸び

と，低降伏比が達成できていると言える。

\section{6.おわりに}

世界的なエネルギー需要増加とより $\mathrm{CO}_{2}$ 排出量の少な いエネルギーへの転換を背景とした天然ガス輸送用パイ プラインの開発は今後も続くことが予想される. 長距離パ イプラインの建設, 操業コストの低減が可能な X100 グレ ード以上の高強度ラインパイプの本格的な適用が期待さ れている.しかし，パイプラインの敷設環境は，極寒地域 や地震・凍土地帯などより厳しくなっており, パイプライ ンの安全性をより確かなものとするためには, 継続的な材 料開発が必要である。また，ECA（Engineering Critical Assessment）と呼ばれる性能評価及び設計手法の開発と その適用も進み, 材料性能の限界を把握してょり合理的な パイプライン設計も行われるようになってきている．X80 グレードを超えるようなパイプラインにおいては, 材料開 発のみならず設計技術や溶接施工技術の開発も不可欠で あり，材料，設計及び施工の連携がさらに重要になると考 えられる。

\section{参考文献}

1) N. Sanderson, et al.: Oil \& Gas Journal, March 15 (1999), 54-57.

2) A. Glover: Proc. of Application \& Evaluation of High Grade Linepipe in Hostile Environments Conf. (2002), Yokohama.
3) T. Masuda, et al.: Proc. International Pipeline Technology Conference, Ostend, Belgium (2004), 31-40.

4) H. Gao, et al.: Proc. 16th International Offshore and Polar Engineering Conference, Lisbon, Portugal (2007), ISOPE 2007-SDB-50.

5) A. Glover, et al.: Proc. 22nd International Conference on Offshore Mechanics and Arctic Engineering, Cancun, Mexico (2003), OMAE2003-37429.

6) H. Asahi, et al.: Proc. 13th International Offshore and Polar Engineering Conference (2003), 19-25.

7) S. Okaguchi, et al.: Proc. 13th International Offshore and Polar Engineering Conference (2003), 36-42.

8) H. G. Hillenbrand, et al.: Proc. 5th International Pipeline Conference (2004), IPC04-0224.

9) N. Ishikawa, et al.: Proc. 26th International Conference on Offshore Mechanics and Arctic Engineering (2007), OMAE2007-29561.

10) N. Ishikawa, et al.: Proc. 20th International Conference on Offshore Mechanics and Arctic Engineering (2001), OMAE2001/MAT-3100.

11) Y. Terada, et al.: Proc. of 22nd International Conference on Offshore Mechanics and Arctic Engineering (2003), OMAE2003-37391.

12) A. Glover, et al.: Proc. International Pipeline Conference, Calgary, Canada (2004), IPC04-0328.

13) F. Marchesani, et al.: Proc. Super-High Strength Steels, Rome, Italy (2005).

14) J. Johnson, et al.: Proc. International Pipeline Conference, Calgary, Canada (2008), IPC2008-64653.

15) N. Ishikawa, et al.: Proc. International Pipeline Conference, Calgary, Canada (2008), IPC2008-64506.

16) 石川信行ほか：CAMP-ISIJ, 14 (2001), 573.

17) T. Huper, et al.: ISIJ International, 39 (1999), 288-294.

18) N. Ishikawa, et al.: Proc. 6th International Pipeline Conference (2006), IPC2006-10240.

19) S. A. Blackman, et al.: Proc. International Pipeline Technology Conference, Ostend, Belgium (2004), 335-355.

20) V. Rajan, et al.: Proc. 6th International Pipeline Conference (2006), IPC2006-10358.

21) 朝日 均：溶接学会誌, 74-7 (2005), 14-19.

22) H. Asahi, et al.: Proc. 13th International Offshore and Polar Engineering Conference (2003), 19-25.

23) S. Okaguchi, et al.: Proc. 13th International Offshore and Polar Engineering Conference (2003), 36-42.

24) H. G. Hillenbrand, et al.: Proc. 5th International Pipeline Conference (2004), IPC04-0224.

25) N. E. Biery, et al.: Proc. 6th International Pipeline Conference (2006), IPC2006-10397.

26) R. Bruschi: X100 Forum-CSM-Pura(Sardinia), (2006).

27) H. Asahi, et al.: Proc. 6th International Pipeline Conference (2006), IPC2006-10087. 